\title{
Implementation planning for information systems: promoting the transition with a communication strategy
}

\author{
T. McMaster \& R. T. Vidgen \\ Information Systems Research Centre \\ University of Salford \\ M5 4WT \\ $U K$ \\ Tel : +44161745 5000 \\ Fax : +44161745 5559 \\ Email T.McMaster@mcs.salford.ac.uk \\ R.T.Vidgen@mcs.salford.ac.uk
}

\begin{abstract}
Too many information systems fail, and sometimes this is due to poorly planned, or unplanned implementation procedures. We discuss the meaning of failure and the role of design in this context, and we propose an implementation planning model which takes soft human issues into account. Our model borrows tools and methods from the marketing domain, and particularly from marketing research disciplines which have a long tradition of investigating qualitative issues for the purpose of promoting new products and services.
\end{abstract}

\section{Keywords}

Information systems, implementation, technology transfer, design, failure

\section{INTRODUCTION}

Who can count the cost of Information Systems failures? If Lyytinen and Hirschheim (1987) are in any way accurate, at least half of all systems fail, and very likely an even higher proportion than that. At worst, these failures have resulted in the loss of lives, as was the case in the failure of the London Ambulance Service Dispatch System in 
1992 (Robinson, 1994). Even in less extreme circumstances however, IS failures represent an enormous waste of an organization's resources. To quantify this in terms of hard cash is not easy if indeed it is possible or even desirable. However when we consider that the 500 or so Local Government Authorities in England and Wales for example, a mere pixel in the bigger cross-sectorial, trans-national picture, allocated more than an estimated one thousand million pounds to IT expenditure in 1993 alone (Miles, 1990), we can begin to see that globally we are looking at a problem of enormous proportion.

Some of these failures are due to poorly planned or unplanned implementation procedures (Lyytinen \& Hirschheim, p. 291), though we recognize (and we caution others to do so), that viewing the implementation of information systems as a separate activity to information systems design (ISD), may well be inviting or inventing the very problem which it seeks to alleviate. Nevertheless despite more than two decades of observation and insight into the design and development processes of IS by researchers, consultants and practitioners, and in particular by those associated with what has come to be known as the 'Scandinavian Tradition' (cf. Bansler, 1989, Bjerknes \& Bratteteig, 1989, Bødker et al., 1989, Ehn \& Kyng, 1989, Grønbæk, 1990, etc.), where much emphasis has been placed on the importance of user-participation in IS design and development, still individual managers too often resolve to build or buy new systems without consulting or involving users and other stakeholders. When the subsequent implementation process fails, no one seems more surprised than they do.

This paper proposes that including what we have chosen to call a communication strategy as a core component of an implementation plan, may greatly facilitate successful technology transfer into organizational settings. We believe that such a strategy can help to reduce the risks and propensities for such systems to fail. For one thing, it involves the would-be implementor developing a dialogical relationship with the intended user or other stakeholders (late in the process though this may be), and for another, it focuses the attentions of those involved on the implementation process itself. These may be the minimum requirements for the successful implementation of any new technology into the workplace.

We use the term 'implementation' in this paper rather broadly. This includes decisions and actions which are intended to lead to, and are directly concerned with the transfer and the adoption of information (and other) technologies into organizational settings. This may include the introduction of 'new' technology into technologically mature organizations, for example a new database application into a situation where database technologies have already been accepted, routinized and infused (Saga and Zmud, 1994). On the other hand it might also mean the introduction of new or even novel technologies into technologically naive organizations. We may speculate as to whether or not it may be easier to introduce new technical systems into the one rather than the other, but what we do know is that introducing new information technology, even into professional IT departments, can and does fail (Kautz and McMaster, 1994). Generally speaking therefore, it would appear that the technical competencies of stakeholders may have little direct bearing on the success or otherwise of the project, and it may well be that problems with new technology are more often than not, problems of a non-technical nature.

We make some references in this paper to a case study which has been reported in more detail elsewhere (McMaster et al., 1995, and Vidgen \& McMaster, 1995). This concerns an attempt to introduce a new information and control system into the car parking arrangements in a British University. Clearly the wider organization consists of 
many highly-skilled individuals, some of whom enjoy a high level of technical fluency in their professional roles, though this is not necessarily true in their more fleeting roles in the abstracted car park organization. For the purposes of this paper, we regard the car park sub-system of the wider organization with its various stakeholders (managers, administrators, car park attendants, users, etc.) to be an 'organization' in its own right.

The main argument in this paper may be expressed quite simply: technical systems sometimes fail due to poorly planned or unplanned implementation processes. By failure, we mean simply that for one reason or another, the intentions for the system have been abandoned before it has become, in the words of Saga and Zmud (ibid.), embedded in the organization's work systems. We contend that system failures are sometimes due to a failure by the dominant coalition (this may be an individual manager) to recognize and take into account the fact that there are social consequences associated with introducing technical artefacts into organizations, and that these consequences can assist or impede, or even destroy the envisioned outcome.

We argue that a shift is needed towards a wider concept of design. The traditional IS design perspective reflects a rather narrow technical and 'product-oriented' view (such as that described by Floyd, 1987), while we propose that a 'customer-oriented' view which encompasses social, political, ethical, aesthetic and other issues (Stolterman, 1992), is both necessary and desirable. We present a prototype implementation model to assist this process, at the heart of which lies a communication strategy. To develop this, we borrow ideas from soft systems methodology (SSM), and from marketing disciplines. Since marketing has long been concerned with factors such as customer satisfaction, value and quality, we feel that the IS community might benefit from ideas imported from this domain. This work is formative, but some theory testing is currently underway.

\section{IS FAILURE AND IS DESIGN}

\subsection{Information systems failure}

Failure is a qualitative, subjective judgement, and just as difficult a concept to pin down as the notion of quality itself, with which it shares certain features. For example, failure is described by Bignell and Fortune (1984) as an assessment of the outcorne of an activity which is based upon the values of the person making the judgement.

Service quality is similarly described by Parasuraman, et al. (1985) as a comparison between expectations and performance, and evaluations which involve outcomes and processes. Just as quality may mean different things to different people (cf. Garvin, 1984), so too, what is seen as failure by one person, may not be regarded as failure by another. Just to further complicate the issue, what may have been seen as failure yesterday, may not be regarded as failure today, highlighting the notion that failure needs to be viewed in a historical context. Like quality, failure is a construct which is both elusive and indistinct.

According to Lyytinen and Hirschheim (1987), IS failures can be classified into one of four types. These are correspondence failure, process failure, interaction fcilure and expectation failure. Correspondence failure means that design objectives have not been met (tending to reflect a management view of failure). Process failure relates to the ISD process where budgetary, time or other resource allocations have overrun to the point where any benefits expected from the proposed system have been negated, or 
where the allocated resources do not result in a workable system. Interaction failure is an argument that the low-level use of the system can be interpreted as failure, and expectation failure is simply that the system has failed to meet the expectations of at least one stakeholder group. On the basis that the expectations of any stakeholder group are not met, then the situation can be regarded as a failure. Lyytinen and Hirschheim (ibid.) take the view that the first three classes of failure may be subsumed by expectation failure, since this is essentially a superset of the others.

We now turn our attention to the relationship between design, and IS failures.

\subsection{Design and IS failure}

Design in the context of information systems has a variety of meanings. Clare and Stutely (1995) for example describe (system) design as a stage in the development life cycle which produces as its deliverable 'detailed system specifications' (pp. 213-214). These consist of input details (devices, screen layouts, forms etc.), output details (ditto), database details, and computer and associated manual procedures such as algorithms, program structures, process diagrams and data diagrams. This seems positively liberal when we read that programming - an activity stage in the IS development process, is about designing machine behaviour that can assist or even replace humans in intellectual tasks (Hoc et al, 1990, p.3). Design in formal structured methods such as SSADM for example, aims to construct modules which 'mirror' the real world (Downs et al., 1988, p. 7), the implication being that the designer is somehow a detached and impartial observer, skilled at making objective pronouncements on the nature of organizational reality.

Each of these examples reflects a hard 'product-oriented' view of information systems (Floyd, 1987) which is deeply rooted in the positivist traditions of Western European thought. From this perspective, design is reduced to a mechanistic, efficiency-driven set of choices related to machine components (including people), where system development projects are nothing more than solutions built to repair a malfunctioning reality (Stolterman, 1992).

We feel that we must reject such views which assume an objective reality 'out there' that can be measured using modern scientific techniques and methods. Instead, we subscribe to a constructivist philosophy, whose proponents, including for example Floyd (1992), Dahlbom (1992) and Burstall (1992) among others, acknowledge the active role which we bring to our perception and understanding of reality. The emphasis in constructivist thought, is on the observer constituting reality, and inventing suitable descriptions (Floyd, 1992). This means that 'choice' becomes an important ingredient in the process, and there is therefore greater scope for design, and design decisions. Stolterman (ibid.) uses the term 'design process' to describe a highly complex kind of human activity concerned with meeting the demands of factors such as economy, function, aesthetics, ethics, politics, environment and others, while Schön (1983) describes design as a reflective conversation with the situation.

We prefer this broader notion of design, because it allows us to consider stakeholder factors such as feelings, concerns and emotions, and to design systems and implementation strategies with much more care and consideration for humans. From such a perspective we view the classes of information systems failure detailed by Lyytinen and Hirschheim (ibid.), each as design failures. 'Correspondence failure' is admitted by those authors as design failure, but 'process failure' may also be seen as a design failure. If for example, we were to instruct a graphic designer to produce a 
letter-head for us, for $£ 500$ in one month's time, to be later told that it would cost $£ 1000$ and take two months, we may well consider this to be a serious design problem. Design should also incorporate resource constraints where these are previously specified and agreed.

'Interaction failure' may also be seen as design failure, since systems are not designed not to be used. The subsequent low use or non-use of the system may therefore be considered as falling short in certain design considerations. This is supported by Ovaska (1991), who argues that 'usability problems' can be solved by better design and development efforts, and Bødker (Bødker, 1987 quoted in Ovaska, ibid.) has stated that the user interface cannot be seen independently of the goal of the user, or of the other conditions of the use activity. Since information systems are designed to be used, then the failure to use them, is a failure in design.

'Expectation failure' suggests that no consideration was given to the needs of at least one stakeholder group. This may be due to a tendency for traditional system development approaches to consider users as a single homogenous group. A stakeholder perspective however, recognises that the system will affect and be affected by sometimes a large number of groups, each with their own sets of needs and concerns. Our model for designing an implementation strategy includes the explicit identification of as complete a set of stakeholders as possible, and one of its aims is to help each of them construct appropriate expectations for the proposed new system.

For us, design is a complex set of considered planning activities, whose interests include stakeholder concerns and other soft issues including the 'use' of information systems and their associated technologies. Any issue which can affect the success of technology transfer is for us a legitimate area for the application of design decisions, and we would argue that in these areas 'failing to design' may be 'designing to fail'.

\section{RESEARCH MOTIVATIONS}

In the introduction we stated that some at least of the many putative IS failures may be attributable to a failure to design (plan) the implementation process with sufficient rigour or thoroughness. We undertook a mini-survey to test this assumption, and we also draw on our recent experiences of a case study. These have served as motivators for this paper, and we present brief details in this section.

\subsection{Survey}

In January 1995, ten local authority IT managers were contacted, and of these eight agreed to discuss with us their IS/IT implementation practices. The ten contiguous District Councils used to make up what was Greater Manchester County, prior to its dissolution by a former Thatcher administration. This is significant, because the very close relationships which the various authorities in the conurbation once had have not disappeared, and there are still strong links, some informal, between the districts. One such forum is known as the Greater Manchester IT Group. This comprises the ten respective IT Department Managers, who meet approximately every three months to discuss issues of common interest. The importance of this as far as our purposes are concerned, is that because of such arrangements, there may be a tendency towards homogenous problem-solving strategies - a kind of 'groupthink' (Janis, 1971), which in turn is likely to limit our ability to generalize from observations and interpretations 
based solely on this group. On the other hand, it does provide us with some insight into practices in a specific type of organization.

A number of semi-structured interviews took place. Six of these were conducted by telephone, generally lasting not more than ten or fifteen minutes, and two were conducted face-to-face, with a duration of between twenty and thirty minutes. The interviewees are all senior managers within their respective Councils' IT Departments.

Our respondents confirmed our suspicions that traditionally little real planning for the implementation of new systems has taken place. The extent to which it had, was generally limited to a simple incremental stage model, where each step in the process represents for example a unit of time, a department in the organization, a module of the system, or some loose combination of these. This might take a form such as, implementing a module of the system in the accounts section by July, then into another section by August, for example. A product-centred view of the process prevails, with recognition that training may often be required by some 'users', prior to a new system going live. Training issues are possibly the only people matters to enter the equation, but even this has a technically-driven, positivist flavour to it, with managers deciding who receives training, and when..

All of our respondents were concerned about what they felt was a need to improve their traditional practices, as government legislation forces them to adapt to a competitive environment. Compulsory competitive tendering (CCT) will mean that they will no longer be the sole providers of IT/IS services operating in a monopolistic culture. Instead they will have to win contracts from their existing customers, very likely against highly professional and very determined competitors.

\subsection{Case study}

In 1993, an Institute of Higher Education in the UK purchased a new automatic access control system for each of its three main car parking areas. Despite winning a Gold Award, four weeks after becoming operational during which there were 4 accidents, the system was shut down. The system has a number of unconventional features, including proximity cards, retractable steel bollards, and an 'invisible' card reader which we briefly describe.

\section{- Froximity card technology}

These are cards that resemble 'magic wands' in the sense that they need only be waved around close to the 'reader', rather than inserted into a slot in order to operate the system. The cards each contain a unique code which has been allocated to the card holder. When this is presented to the system, a check is made against a database image which is downloaded periodically from a PC to the site computer, via modem links, for validation. The system also includes a more conventional 'slot' into which a token may be inserted, for casual users or visitors. 


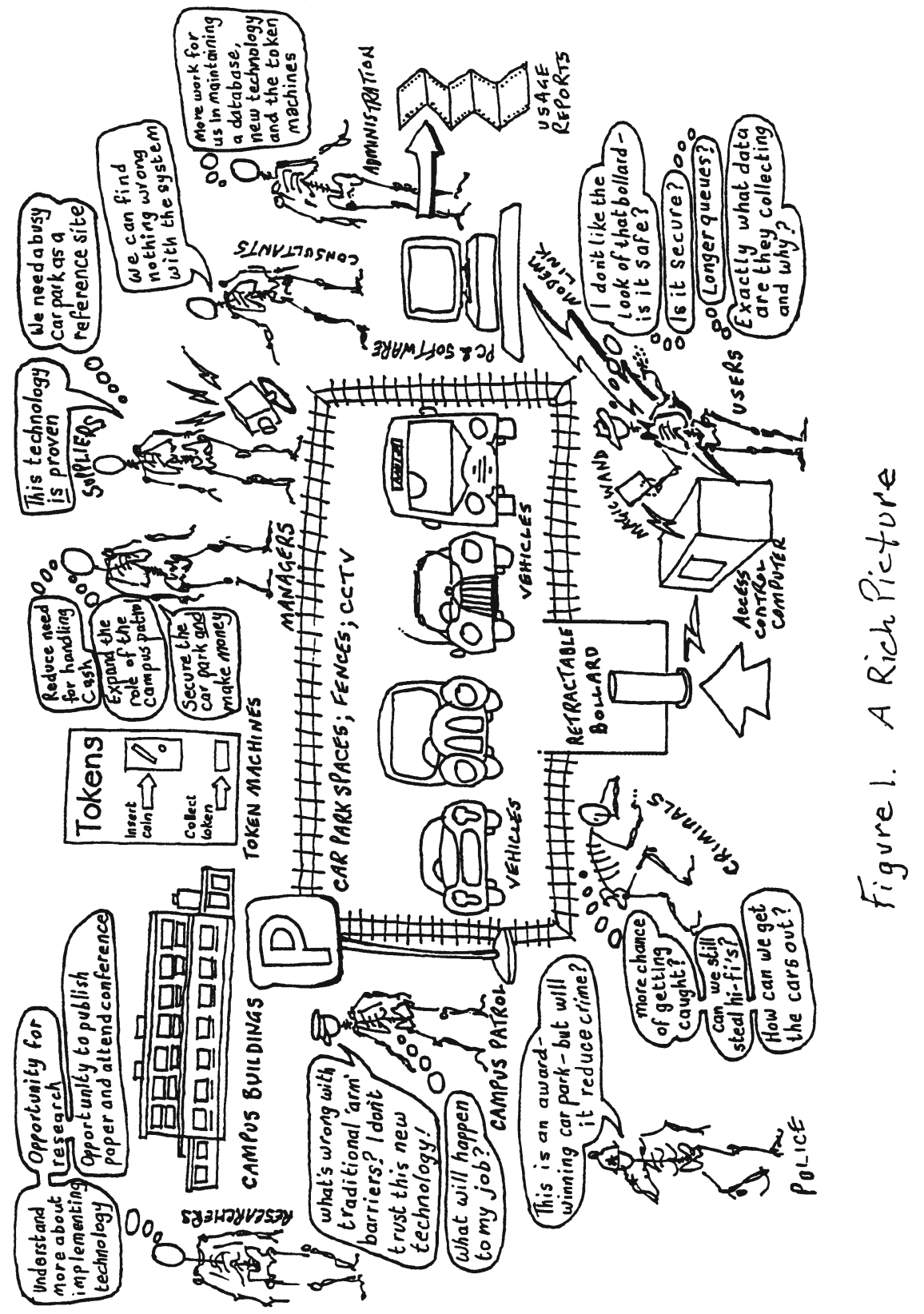

Figure 1: A Rich Picture 


\section{- Retractable steel telescopic bollards}

These are unusual compared with the more conventional 'arm' type barrier with which most drivers are familiar. When retracted, these bollards are flush with the ground. Related to these, there are three induction loops embedded in each of the access roads, and these are designed to detect the presence of motor vehicles in the system. These are critical to the safe operation of the system, for if a vehicle were unfortunate enough to stall over the bollard for example, its detection on the loop ensures that the bollard remains retracted.

\section{- Hidden card reader}

The card reader is housed within a brick structure, and is therefore not visible to the user. There is a metal plate on the brick housing which indicates where the proximity card should be generally waved about, but there is no direct access to the reader, which picks up the code programmed into each card. The system has other unusual features, but those which we have described are most relevant for our purposes, since they form the main interface between the users and the system.

Within four weeks of implementing this system, there were four accidents which involved vehicles colliding with the bollards, causing damage to the vehicles. Following the final accident the systems were shut down by the organization's managers, and they have remained so, since. The system is almost universally regarded as a 'failure' by car park attendants (Campus Patrol), staff and student users, by administrators and by managers in the organization. We were curious.

Briefly, we found a number of interesting factors including:

- significant stakeholders had serious concerns about the system (car park attendants were worried how it would affect their jobs, users were worried about the safety of this novel (radically different) technology for example);

- no attempts were made to identify or address these concerns;

- stakeholders were not involved in design process;

- misgivings expressed by a campus patrol representative were ignored;

- no attempt was made to promote benefits of the system, nor was any explanation given for the choice of technical components;

- misuse of system (tailgating) by users was encouraged by Campus Patrol staff, and had become routine practice.

Since we advocate in our planning framework the use of rich picture techniques for stakeholder identification, we include a rich picture of the case (figure 1), which shows the principal stakeholders, and some of their feelings and assumptions, in speech and thought bubbles. From these, conflicts and other organizational relationships between stakeholders can be identified. No great significance should be made of the fact that in our illustration, the car park appears as the central focus of the situation. We do not suggest that the technical system is to be considered as more important than other components of the diagram, but this composition was helpful, since it allowed us to think about the situation using the car park as the focus for our study (Vidgen and McMaster, 1995). 


\section{IMPLEMENTATION PLANNING FRAMEWORK}

\subsection{Implementation planning}

Implementing a new system needs to be a designed (planned) activity. Consideration needs to be given for example, to the installation of both the hardware and the software components, site commissioning, and system changeover processes (Yeates, et al., 1994). Yet, important as these things may be, they are not the only concerns, nor are they we suspect, overly-neglected aspects of systems implementation in any event. What we are interested in, are those elusive and unpredictable factors of human concern.

\subsection{An implementation planning model}

The model we propose (figure 2) by no means rejects incremental, staged introduction processes. We see it rather as adding a further, human dimension to it, through the process of developing and including a communication strategy.

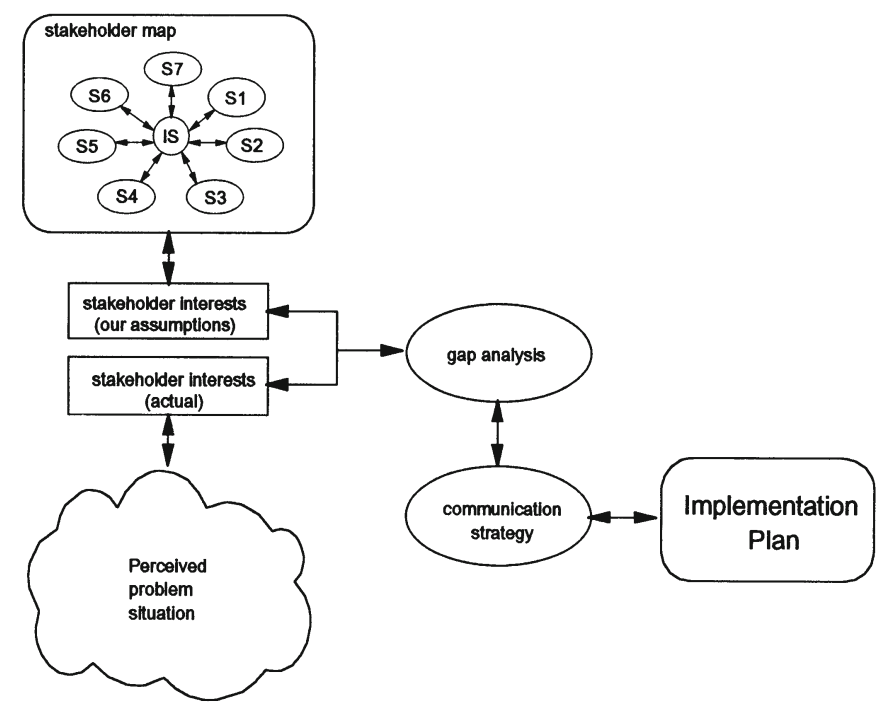

Figure 2: An implementation planning model

The purpose of the strategy is to promote the benefits, and eliminate or reduce fears and concerns about the system which may be unique to particular groups. This strategy aims to address the needs of all identified stakeholder groups, and in order to accomplish this purpose will give consideration to the content as well as to the mode of delivery. For example, the Campus Patrol officers were concerned about the effect of the technology on their jobs, and it would have been appropriate for management to 
address this issue. There was (and is) no intention that the technology should replace any of these staff, but that their roles might be extended to allow them to actually 'patrol' the campus, instead of confining them to car park access points. Since this is a relatively small group, direct briefings by senior managers may have been an appropriate mode of delivery, and may have allowed opportunities for concerns to be aired. Instead, there was no communication on the subject, and the group were left to speculate about the precise nature of the role of the new technology, and how it might affect their jobs.

The communication strategy might equally be called a 'marketing information strategy', since it performs a marketing function. Marketing, put very simply, seeks to identify consumer needs through research activities, and to influence the consumer's wants and demands by providing effective satisfactions for those needs. Similarly, the communication strategy in our implementation plan, seeks to provide satisfactions to emotional and informational needs related to the social impact of the system, which have been identified through a research process. Since each stakeholder group will have different needs, the communication strategy therefore consists not of a single plan, but a set of plans, each of which is targeted at a specific group.

We give a brief description of components in the model, starting with stakeholder identification and analysis.

\section{Stakeholder identification}

Stakeholders, according to Mitroff and Linstone (1993) are 'any individual, group, organization, institution that can affect as well as be affected by an individual's, group's, organization's, or institution's policy or policies'. In order to identify them, we propose the use of rich picture techniques. The rich picture is a Soft Systems Methodology (SSM) technique that allows a complex problem situation to be expressed informally, including relationships and value judgements, and they are helpful in gaining an heterogeneous understanding of the situation. It is intended to be a creative expression of possibly conflicting viewpoints rather than a representation of some 'objective reality'. In this respect it reflects a constructivist view, which is in line with our own standpoint. There is no formal notation for the technique, although some conventions (such as crossed swords to indicate conflict, for example), have been used. This representation of a situation assists us in identifying the stakeholders.

\section{Stakeholder interest analysis (our assumptions)}

Stakeholders are identified and represented diagramatically in a stakeholder map. This is represented in our model (figure 2) as S1, S2 etc. The analyst, together with project team members analyze stakeholder interests and surface the assumptions that the project team consider the stakeholders to have. These are the assumptions that need to hold if the IS implementation is to be successful. They are not necessarily the assumptions that 'real' stakeholders hold.

\section{Stakeholder interest analysis (actual)}

Mitroff and Linstone (1993, p. 144) provide a matrix against which stakeholder assumptions can be plotted. The vertical continuum maps the degree of certainty of the assumption, and the horizontal, the importance. For those assumptions which we think are important and uncertain, the project team might wish to undertake a deeper exploration of the problem situation. For instance, in our example of the car park, the 
project team might assume that car park users are a homogeneous group whose interests are personal security, and vehicle security. Investigation in the 'problem situation' (figure 1) might lead to the identification of a number of sub-groups such as car drivers, motor-cyclists, coach drivers, staff, students, and visitors. They may also have divergent interests. Membership of a stakeholder group is not necessarily exclusive, and individuals may belong to more than one sub-group.

Stakeholders may have beliefs and attitudes that are not congruent with the assumptions adopted by the project team. Problem situations tend to be messy since they are populated by individuals; our neat stakeholder map might prove to be a sterile and banal over-simplification. It is in this area that some of the techniques of marketing research, a mature discipline with a wide range of methods, might be fruitfully deployed.

\section{Methods and Tools}

Qualitative techniques used in marketing research provide a wide range of methods and tools, including 'depth interviews', and 'projective' techniques for example. These are particularly useful tools when the use of direct structured questionnaires may not be possible, either because the interviewee is unwilling, or is unable to respond. This may be because the questions adversely affect their self-perception or prestige, or concern motivations that they do not understand, or cannot verbalize (Tull and Hawkins, 1993, pp. 441-442). Such examples may be particularly relevant in circumstances where IS implementation is on the agenda.

Depth interviews may be conducted with individuals, mini-groups (4 or 5 people) or larger, 'focus' groups (8 to 12 people). Each has strengths. Individual depth interviews are useful when detailed probing of individual attitudes, behaviour or needs is required, where the subject matter is of an emotionally charged nature, or where the interviews are with people on the subject of their jobs (Tull \& Hawkins, p. 443). Again, these are all issues of relevance to IS professionals. Mini-group interviews do not allow the detailed investigation of confidential or highly sensitive issues, but do allow detailed probing of 'fairly' sensitive issues to a substantial depth. Focus groups are particularly valuable in establishing the vocabulary as a preliminary step to questionnaire design, and in the determination of attitudes towards a particular issue.

Depth interviews make use of a variety of questioning techniques including 'laddering', 'hidden-issue questioning' and 'symbolic questioning'. Laddering involves respondents identifying attributes (usually of a brand, but of course we envisage a modified application to IS objects). Attributes are then probed to determine their meaning and significance. These reasons are then probed, and so forth. The purpose of this technique is to uncover the 'network of meaning' associated with the object or concept (Tull \& Hawkins, p. 442).

Hidden-issue questions are designed to uncover individuals' feelings about sensitive issues, and the responses are analysed to determine whether or not there may be common underlying themes across a range of respondents.

Symbolic questions reveal feelings about issues by asking the respondents to describe the 'opposites' of the object under investigation. Feelings expressed about the opposite, tell a great deal about feelings toward the object itself, but which might be unlikely to emerge through direct questioning.

Projective techniques offer a repertoire of tools and methods which generally have been adapted from clinical psychology. These include association techniques such as free word association, and successive word association, and their value is often in 
'positioning' the product (system). Completion techniques, such as sentence completion and story completion require the respondent to provide the finishing touches to an incomplete stimulus. The responses provide valuable attitudinal information.

Construction techniques are similar to completion techniques, except that less structure is provided to the respondent. These may include cartoon characters where 'thought bubbles' and 'speech bubbles' are filled in, in response to a stimulus. The rationale is that the speech bubble is likely to draw out the public stance the respondent would take on a particular issue, while the 'thought' bubble is likely to contain the private view.

There are many techniques available for qualitative research, and these few examples merely serve to illustrate the rich and varied source of tools available to IS professionals, from the marketing research domain. These may be especially useful when an understanding of the attitudes and the feelings of the stakeholders may be vital to the success of the introduction process.

\section{Gap analysis}

The 'gap' may be defined as the discrepancy between the implementor's assumptions about stakeholder attitudes in relation to the system, and the actual attitudes of the stakeholders which will be determined from the research activity. These differences may be substantial. Analysis of the gap will result in the identification of objectives for the communication plan. Gap analysis theory is reported to have originated with Weber (1976) for the purpose of guiding the search for growth and opportunity (Kotler, 1994, p.369). Gap analysis techniques have been used more recently for the purposes of improving communication and control processes in the delivery of service quality (Zeithaml, et al., 1988), which, it might be argued, is precisely the business we are in anyway. Our suggestion, is that the gap can provide the directions, the aims and the objectives for our communication efforts with the stakeholders.

\section{Communication strategy}

The communication strategy is a set of plans designed to eliminate, or at least reduce as far as possible, the gap in relation to each stakeholder. It does this by informing, influencing and promoting the benefits of the system in an appropriate and timely manner. It will seek to allay fears and concerns which the stakeholders may hold. In addition to the informational content of each plan, it will also consider the means of delivering that information to the target group, and the time frame for its delivery. Advertising, a mature sub-domain of marketing, offers a range of tools and practices from which IS practitioners might benefit.

\section{$5 \quad$ CONCLUSIONS}

We have indicated that this paper addresses a certain kind of problem, where decisions to acquire a new method or system have already been taken, and where intended users have not been participants in the pre-implementation processes, but how we might ask, can this happen?

Organization theory suggests that this kind of situation might easily occur where the personal interests of the decision-maker do not concur with the interests of the organization (Robbins, 1990), though it has been argued (Knights \& Murray, 1994) 
that 'organizations' have no goals or interests, and that individual aspirations for power and prestige are sold under the guise of organizational direction. Divergent interests mean that the personal interests of individual manager are likely to take precedence over organizational interests (even if these exist), and that motivations behind at least some decisions may be therefore more closely related to issues of personal career enhancement, impressing superiors or peers, or simply plain 'technology pushing', than to organizational goal attainment. This tends to be particularly true in highly bureaucratic organizations such as local government, because excessive bureaucracy encourages 'goal displacement'; the substitution of organizational goals by sub-unit or personal goals (Robbins, ibid., pp. 314-315). In such situations we would hardly expect to see any great regard for users opinions or feelings. This may help to explain the seeming propensity for technology pushing without consulting intended users in some local authorities in the UK, (cf. Ramsey et al, 1992, Hales \& O'Hara, 1993 and Kautz \& McMaster, 1994), but we do not suggest that such practices are confined to this sector, nor indeed do we suggest that there are no good practices to be found here.

We believe our implementation model can help to reduce the risks of failure, even at such a late stage, because it requires dialogue with, and the involvement of stakeholders. So far however, our proposition is formative, and research is needed in the application of the model in order to illuminate areas that we have perhaps taken for granted, or that we assume are not problematical. The organization in which the case was interpreted, is about to attempt to re-implement the 'failed' car park system, and one of this paper's authors is providing advice to senior management who have agreed to employ a strategy based upon our model. It is too early to report on the process, except to say that stakeholder analyses have taken place and a number of briefing sessions have been undertaken with Campus Patrol staff, administrators and other staff so far. These have attempted to address the respective concerns of the stakeholders, and to educate and inform them about the role that the system is intended to play in the long term security strategy for the campus, and how they are likely to be affected by it. In addition, a draft document has been drawn up which will form the basis of the communications strategy with users, and the intention is that they will individually contacted through the internal mail system. An article has been prepared for the campus newspaper, and a help-line is to be set up. We are currently waiting for a number of physical modifications to be carried out, before the next stage of the reimplementation process can take place, and we look forward to reporting the process and outcomes in due course.

\section{REFERENCES}

Bansler, J., (1989) 'Systems development research in Scandinavia: three theoretical schools', in Scandinavian Journal of Information Systems, Vol. 1, pp. 3-20.

Bignell, Victor, and Fortune, Joyce, (1984), Understanding Systems Failures, Manchester University Press in association with the Open University.

Bjerknes, G., and Bratteteig, T., (1989), 'Florence in Wonderland: System Development with Nurses', in G. Bjerknes, P. Ehn and M. Kyng (Eds.) Computers and Democracy, A Scandinavian Challenge, Avebury, pp. 279-295

Bødker, Susanne, (1987), 'Through the Interface -- A Human Activity Approach to User Interface Design', Ph.D. Thesis, DAIMI PB-224, Aarhus University. 
Bødker, S., Ehn, P., Kammersgaard, J., Kyng, M., and Sunblad, Y., (1989), 'A UTOPIAN Experience: On Design of Powerful Computer-Based Tools for Skilled Graphic Workers', in G. Bjerknes, P. Ehn and M. Kyng (Eds.) Computers and Democracy, A Scandinavian Challenge, Avebury, pp. 251278.

Burstall, Rodney, M., (1992), 'Computing: Yet Another Reality Construction', in Floyd, C., Züllighoven, H., Budde, R., and Keil-Slawik, R., (Eds.), Software Development and Reality Construction, Springer-Verlag, pp. 45-51.

Clare, Chris, and Stuteley, Gordon, (1995), Information Systems - Strategy to Design, Chapman Hall.

Dahlbom, Bo, (1992), 'The Idea that Reality is Socially Constructed', in Floyd, C., Züllighoven, H., Budde, R., and Keil-Slawik, R., (Eds.), Software Development and Reality Construction, Springer-Verlag, pp. 101-126.

Dahlbom, Bo, and Mathiassen, Lars, (1993) Computers in Context: The Philosophy and Practice of Systems Design, NCC Blackwell, Cambridge, MA \& Oxford UK.

Downs, E., Clare, P., Coe, I., (1988) Structured Systems Analysis and Design Method: Application and Context, Prentice Hall.

Ehn, P., and Kyng, M., (1989), 'The Collective Resource Approach to Systems Design', in G. Bjerknes, P. Ehn and M. Kyng (Eds.) Computers and Democracy, A Scandinavian Challenge, Avebury, pp. 17-57.

Floyd, C., (1987), 'Outline of a Paradigm Change in Software Engineering', in G. Bjerknes, P. Ehn and M. Kyng (Eds.) Computers and Democracy, $A$ Scandinavian Challenge, Avebury, pp. 191-210.

Floyd, C., (1992), 'Human Questions in Computer Science', in Floyd, C., Züllighoven, H., Budde, R., and Keil-Slawik, R., (Eds.), Software Development and Reality Construction, Springer-Verlag, pp. 15-27.

Garvin, David, A., (1984) 'What does “Product Quality" Really Mean?' in Sloan Management Review, Fall, 1984, pp. 25-43.

Grønbæk, Kaj, (1990), 'Supporting Active User Involvement in Prototyping.', in Scandinavian Journal of Information Systems, Vol. 2, pp. 3-24.

Hales, Mike, and O'Hara, Peter, (1993), 'Strengths and Weaknesses of Participation: Learning by Doing in Local Government', in Green, E., Owen, J., and Pain, D., (Eds.), Gendered by Design? Information Technology and Office Systems, Taylor and Francis, pp. 153-172.

Hoc, J., -M., Green, T., R., G., Samurçay, R., and Gilmore, D., J., (1990), Psychology of Programming, Academic Press, London, San Diego, New York, Boston, Sydney, Tokyo

Janis, Irving, L., (1971), 'Groupthink: The Desperate Drive for Consensus at Any Cost', in Psychology Today Magazine, Sussex Publishers, Inc.

Kautz, Karlheinz, and McMaster, Tom, (1994), 'The Failure to Introduce System Development Methods: A Factor-Based Analysis.', in Levine, L., (ed.), Diffusion, Transfer and Implementation of Information Technology, Elsevier / North Holland, Amsterdam, London, New York, Tokyo. pp. 275-287.

Knights, David, and Murray, Fergus, (1994), Managers Divided: Organisation Politics and Information Technology Management, Wiley.

Kotler, Philip, (1988), Marketing Management: Analysis, Planning, Implementation and Control, 6th edition, Prentice-Hall International Editions. 
Lyytinen, Kalle, and Hirschheim, Rudy, (1987), 'Information Systems Failures--a survey and classification of the empirical literature', Oxford Surveys in Information Technology, Vol. 4, pp. 257-309, Oxford University Press.

McMaster, Tom, Jones, Mark, C., and Wood-Harper, A., T., (1995) 'Implementation Planning: A Role for an Information Strategy?', 3rd Decennial Computers in Context - Joining Forces in Design, Aarhus, Denmark.

Miles, Ian, and contributors, (1990), Mapping and Measuring the Information Economy, Library and Information Research Report 77, The British Library Board, p.157.

Mitroff, Ian, I., and Linstone, Harold, A., (1993), The Unbounded Mind: Breaking the Chains of Traditional Business Thinking, Oxford University Press.

Ovaska, Saila, (1991), 'Usability as a Goal for the Design of Computer Systems', in Scandinavian Journal of Information Systems, Vol. 3, pp. 47-62.

Parasuraman, A., Zeithaml, V., A., and Berry, L., L., (1985), 'A Conceptual Model of Service Quality and its Implications for Future Research', in Journal of Marketing, Vol. 49, pp. 41-50.

Ramsey, Harvey, Baldry, Chris, Connolly, Anne, and Lockyer, Cliff, (1992), 'Computerizing the Council: IT, jobs and employee influence in a local authority', in Ramsey, H., and Beirne, M., (Eds.), Information Technology and Workplace Democracy, Routledge, pp.146-172.

Robbins, Stephen, P., (1990), Organization Theory: Structure Designs and Applications, 3rd edition, Prentice-Hall International, Inc.

Robinson, Bruce, (1994) 'Social Context and Participant Understanding of IS Failure', in Proceedings of the 2nd BCS Conference on IS Methodologies, Edinburgh, 1994.

Saga, V., L., and Zmud, R., W., (1994) 'The Nature and Determinants of IT Acceptance, Routinization, and Infusion', in Levine, L., (ed.), Diffusion, Transfer and Implementation of Information Technology, Elsevier/North Holland, Amsterdam, London, New York, Tokyo. pp. 67-86.

Schön, D., A., (1983), The Reflective Practitioner: How Professionals Think in Action, Basic Books.

Stolterman, E., (1992) 'How System Designers Think About Design and Methods', Scandinavian Journal of Information Systems, Vol. 4, pp 137-150

Tull, Donald, S., and Hawkins, Del, I., (1993) Marketing Research, Measurement and Method, 6th edition, Macmillan.

Vidgen, R. T., (1994), 'Information Systems: identifying customers and understanding quality requirements', in Proceedings of the 17th IRIS, Syöte, Finland.

Vidgen, Richard, T., and McMaster, Tom, (1995), 'Black Boxes, Non-human Stakeholders, and the Translation of IT through Mediation', Proceedings of IFIP8.2 Conference on Information Technology and Organizational Change, Cambridge, 1995.

Weber, John, A., (1976), Growth Opportunity Analysis, Reston Publishing Company.

Yeates, Don, Shields, Maura, and Helmy, David, (1994), Systems Analysis and Design, Pitman Publishing.

Zeithaml, Valarie, A., Berry, Leonard, L., and Parasuraman, A., (1988), 'Communication and Control Processes in the Delivery of Service Quality' in Journal of Marketing, April 1988, Vol. 52, pp. 35-48. 